\title{
A UTILIZAÇÃO DE DERIVATIVOS AGREGA VALOR À FIRMA? UM ESTUDO DO CASO BRASILEIRO
}

DOES THE USE OF DERIVATIVES ADD VALUE TO THE FIRM? A STUDY USING BRAZILIAN DATA

\section{RESUMO}

Este trabalho examina o uso de derivativos e seu impacto sobre o valor da firma para uma amostra de empresas brasileiras não-financeiras listadas na bolsa de valores de São Paulo, no período de 1996 a 2006. Utilizando métodos paramétricos e não-paramétricos, os resultados confirmam que a utilização de derivativos agrega valor à firma e indicam que, contrário ao previsto por Modigliani e Miller (1958), a política financeira das empresas exerce um impacto sobre o seu valor.

\section{José Luiz Rossi Júnior}

Professor do Departamento de Administração e Economia, Ibmec São Paulo

JoseLRJ1@isp.edu.br

Recebido em 27.03.2008. Aprovado em 11.08.2008

Avaliado pelo sistema double blind review

Editor Científico: Organizadores do Fórum

ABSTRACT This article examines the use of derivatives and its impact on firm value for a sample of non-financial Brazilian companies listed in the São Paulo Stock Exchange from 1996 to 2006. Using parametric and non-parametric methods, the results confirm that the use of derivatives adds value to the firm, indicating that, differently than asserted by Modigliani and Miller (1958), corporate financing policies do exert an impact on firm-value.

PALAVRAS-CHAVE Derivativos, taxa de câmbio, valor da firma, Q de Tobin, proteção.

KEYWORDS Derivatives, exchange rate, firm-value, Tobin's Q, hedging. 


\section{INTRODUÇÃO}

O mercado de derivativos vem crescendo rapidamente, desde a década de 1980. O desenvolvimento de modelos de precificação, o avanço tecnológico e a maior integração dos mercados financeiros são razões mencionadas como possíveis causas dessa expansão. Embora os dados mostrem a rapidez de tal evolução, a literatura de finanças corporativas ainda não alcançou um consenso se a utilização de derivativos agrega ou não valor ao acionista. Caso as hipóteses de Modigliani e Miller (1958) sejam válidas, a política financeira da firma não terá impacto algum sobre o seu valor. Os autores mostram que, com uma política de investimento fixa, em um ambiente sem fricções, a política financeira da empresa é irrelevante.

Smith e Stulz (1985) discutem que, sendo a política de hedging parte das decisões financeiras das firmas, caso o teorema seja válido, tal política não deve agregar nenhum valor à firma. Os autores argumentam que, caso a firma decidisse alterar sua política de hedging, os investidores poderiam mudar a composição de sua carteira de ativos arriscados com o intuito de anular os efeitos da alteração na política de hedging da empresa, mantendo inalterada a distribuição de sua riqueza futura, fazendo, assim, com que a política de proteção da firma se tornasse irrelevante. Eles concluem que, dessa maneira, somente relaxando algumas das hipóteses de Modigliani e Miller (1958) seria possível que a política de hedging agregasse valor à firma.

Dessa maneira, a resposta a essas questões deveria ser empírica. Mesmo nesse aspecto, a literatura não encontrou um consenso. Os resultados empíricos encontrados mostram divergências com relação ao impacto do uso de derivativos sobre o valor da firma para países desenvolvidos. Allayannis e Weston (2001) encontraram, para os Estados Unidos, um impacto positivo e significativo do uso de derivativos de moedas sobre o valor da firma. Autores como Jin e Jorion (2004), focando empresas norte-americanas do setor de óleo e gás, encontraram um impacto não significativo da utilização de derivativos de commodities sobre o valor da firma. Em contrapartida, Hagelin e outros (2004), em um estudo semelhante com empresas suecas, encontraram evidências de que as atividades de hedge aumentam o valor das firmas e que as empresas que utilizam derivativos são negociadas com prêmio, comparadas às empresas que não os utilizam.

Nenhum dos trabalhos anteriores analisou o impacto da utilização de derivativos em países em desenvolvimento. Este trabalho preenche essa lacuna, pois objetiva analisar o impacto da utilização de derivativos sobre o valor da firma em empresas brasileiras não-financeiras listadas na Bolsa de Valores de São Paulo, no período de 1996 a 2006.

Inicialmente, por meio da utilização de métodos paramétricos de estimação, os resultados confirmam que a utilização de derivativos exerce um impacto positivo e significativo sobre o valor da firma. O estudo mostra também que, além da utilização de derivativos, fatores como tamanho, alavancagem, lucratividade, liquidez, oportunidades de investimento, diversificação industrial e multinacionalidade também exercem impacto sobre o valor das firmas.

Outra contribuição do trabalho é estender a metodologia existente para análise do impacto do uso de derivativos sobre o valor da firma por meio da utilização do método não-paramétrico de propensity score matching para a comparação do valor entre empresas usuárias e não-usuárias de derivativos. Os resultados confirmam que, controlando diversas características das firmas, as empresas que utilizam derivativos apresentam valor superior ao das empresas que não os utilizam, confirmando que o mercado atribui um prêmio para as empresas que adotam políticas ativas de proteção.

O trabalho está organizado da seguinte maneira: inicialmente, realiza-se uma revisão da literatura sobre a utilização de derivativos e seu impacto sobre a firma; em seguida, os dados são apresentados e discutidos; na seção posterior, a metodologia e os resultados são apresentados; e na última seção, são discutidas as conclusões do estudo.

\section{REVISÃO DA LITERATURA}

Modigliani e Miller (1958) mostram que, com uma política de investimentos fixa, sem a existência de fricções (custos de transação, custos de agência e impostos), a política financeira da empresas será irrelevante. Nesse arcabouço, caso a firma alterasse sua política de hedging, investidores alterariam a composição de sua carteira de ativos arriscados, com o intuito de anular os efeitos da mudança na política de hedging da empresa, mantendo inalterada a distribuição de sua riqueza futura, fazendo assim com que a política de proteção da firma se tornasse irrelevante.

Dessa maneira, para que o hedge adicione valor à firma, é necessário relaxar algumas das hipóteses do modelo de Modigliani e Miller (1958). Smith e Stultz (1985) mostram que as empresas podem ter alguns benefícios em reduzir a volatilidade do seu fluxo de caixa, dada a estrutura de taxação vigente ou os custos de financial distress. 
Os autores mostram que, em um sistema de taxação progressiva, o hedge pode reduzir o pagamento esperado de impostos, aumentando a receita após a tributação, elevando, assim, o valor da firma. Eles também mostram que, existindo custos de falência, seria ótimo para as firmas protegerem suas receitas, visto que o hedge reduziria a probabilidade de pagamento desses custos, o que adicionaria valor à firma.

Stulz (1984) relaciona as preferências dos gestores da firma com a prática do hedging. Se os gestores fossem avessos ao risco e sua renda fosse atrelada aos resultados da firma, eles teriam um incentivo para se proteger de flutuações por meio de operações de hedge, já que estas reduziriam a volatilidade do fluxo de caixa da empresa, diminuindo a exposição ao risco. Interessante observar que, nesse caso, o hedge não agregaria valor à firma, pois beneficiaria somente o gestor, não o acionista.

Já Froot e outros (1993) mostram que a intensidade da utilização de derivativos estaria relacionada com a correlação existente entre o fluxo de caixa da empresa e suas oportunidades de investimento futuras. Os autores desenvolvem um modelo no qual as imperfeições no mercado financeiro fazem com que o custo do capital seja proporcional ao seu fluxo de caixa. Portanto, a firma deve proteger o seu fluxo de caixa de flutuações, pois, no caso de um choque negativo, ou a firma toma emprestado a uma taxa mais alta com o intuito de manter seu investimento ou reduz o investimento, gerando um problema de underinvestment.

Demarzo e Duffie (1995) mostram que, mesmo que os acionistas possam realizar a proteção por eles próprios, o hedging será ótimo quando os gestores tiverem informação privada sobre os lucros da firma e desejarem sinalizar isso aos acionistas, porque a qualidade da informação recebida pelos acionistas afeta o valor de sua opção em continuar ou não seu projeto de investimento. O hedging ótimo seria, então, o resultado do dilema entre o grau de informação dos lucros e o custo do hedging.

É extensa a literatura que tenta discriminar, dentre as diversas teorias, os determinantes das atividades de hedging. Judge (2003) resume os resultados de quinze trabalhos sobre o tópico. No geral, o autor encontrou baixo apoio para a importância da taxação ou aversão ao risco dos gestores e da presença de custos de falência na determinação da utilização de derivativos. Como exemplo, somente dois dos 15 trabalhos estudados pelo autor mostraram a existência de um relacionamento entre taxação e a utilização de derivativos pelas empresas. O estudo também indica que os resultados com relação à importância de imperfeições no mercado financeiro são mistos. Metade dos trabalhos confirma a existência de um relacionamento entre oportunidades de crescimento e a utilização de derivativos.

Judge (2003) mostra que a maior parte dos trabalhos indica uma forte evidência de que as economias de escala e a volatilidade do fluxo de caixa em moeda estrangeira são importantes determinantes da utilização de derivativos. Grandes empresas, empresas exportadoras ou com subsidiárias no exterior utilizam mais intensamente os derivativos.

No contexto brasileiro, Saito e Schiozer (2007), por meio de uma survey com empresas não-financeiras, mostram que, a exemplo do que é verificado nos EUA, os gestores das empresas brasileiras usam derivativos com o intuito de gerenciar risco, não com fins especulativos. Ademais, os autores lembram que, diferentemente do que se encontra em outros países, as preocupações principais dos gestores de risco brasileiros estão mais ligadas às questões do arcabouço legal e institucional do que aos aspectos econômico-financeiros. Já Rossi (2007), usando uma amostra de empresas abertas não-financeiras, confirmou que o risco de quebra e a exposição externa são os principais determinantes da utilização de derivativos. Saito e Schiozer (2007) confirmam os resultados de Rossi (2007) com uma amostra de empresas latino-americanas. Os autores mostram que o fato de as firmas nesses países apresentarem dívida em moeda estrangeira é o principal determinante da utilização de derivativos por aquelas, $e$ que, excetuando a taxação, as teorias existentes de hedging ótimo explicam a utilização de derivativos pelas firmas nos países latino-americanos.

Com relação ao impacto da utilização de derivativos sobre o valor da firma, embora a literatura a respeito do tópico não seja tão extensa, também não alcançou um consenso sobre a significância desse impacto. Allayannis e Weston (2001) investigaram se o uso de derivativos afetaria o valor da firma para uma amostra de empresas norte-americanas. Os resultados apresentados pelos autores confirmam a existência de uma relação positiva entre a utilização de derivativos de moedas e o valor da firma. Os autores verificaram que, em média, as empresas com risco cambial que utilizam derivativos têm seu valor 4,87\% maior do que as firmas que não os usam.

Em contrapartida, Jin e Jorion (2004), analisando o comportamento de empresas do setor de óleo e gás no período de 1998 a 2001, identificaram o impacto da utilização de derivativos sobre o valor das firmas do setor como sendo estatisticamente insignificante, quando não com o sinal contrário do esperado. Outros exemplos focando setores econômicos específicos são Carter e outros (2006), Dan e outros (2005) e Lookman (2004). 
Fora dos EUA, Hagelin e outros (2004), em um estudo para empresas suecas, encontraram evidências de que atividades de hedge aumentam o valor das firmas. Os autores identificaram que as empresas que utilizam derivativos de moedas são negociadas com prêmio comparadas às empresas que não os utilizam. Porém, os autores também encontraram evidências de que os gestores que possuem planos de opções de ações da empresa muitas vezes utilizam instrumentos de hedge para proteger a sua remuneração, não o interesse do acionista. Nesses casos, o hedge mostrou uma relação negativa com o valor da firma.

\section{DADOS}

A base de dados utilizada contempla todas as empresas brasileiras não-financeiras listadas na Bovespa de 1996 a 2006, ou seja, que estavam na amostra em 1996 e permaneceram até 2006. Optou-se por essas empresas para que se tenha um painel balanceado. Em um exercício de robustez, a análise foi desenvolvida com todas as empresas não-financeiras de capital aberto que tenham divulgado informações em algum ano. Não foi observada nenhuma alteração nos resultados. No total, foram analisadas 175 empresas.

Os dados foram coletados do site Economática, que fornece informação sobre os dados contábeis e financeiros, diretamente do balanço anual das empresas. Foram excluídas todas as empresas que em algum ano da amostra apresentaram patrimônio líquido negativo, pois essas distorceriam várias medidas utilizadas no trabalho.

O índice Q de Tobin foi utilizado como a proxy do valor da firma. Este é definido como a razão entre o valor de mercado da firma e o custo de reposição dos ativos. Com o objetivo de tornar os resultados comparáveis com os encontrados por Allayannis, Lel e Miller (2007), Allayannis e Weston (2001), Pramborg (2004), o índice Q de Tobin foi calculado da seguinte maneira:

$$
Q 1=\frac{A T-V C E+V M E}{A T}
$$

Em que AT representa o valor contábil dos ativos, VCE é o valor contábil do equity (patrimônio líquido) e VME indica o valor de mercado do equity. Como exercício de robustez, as estimações também serão realizadas com as diferentes definições do $\mathrm{Q}$ de Tobin apresentadas pela literatura.

Os dados sobre a utilização de derivativos foram coletados diretamente do balanço anual das empresas, loca- lizados nas notas explicativas, sob o item "instrumentos financeiros". Importante realçar que uma empresa foi considerada como usuária de derivativos caso tenha informado explicitamente o derivativo usado ou a política de proteção adotada. A instrução CVM 235/1995 (CVM, 1995) regula a publicação da informação acerca da utilização de derivativos pelas empresas. A instrução indica que todas as companhias abertas que possuam instrumentos financeiros, reconhecidos ou não como parte do ativo ou passivo em seu balanço patrimonial, devem evidenciar, em nota explicativa, o valor de mercado desses instrumentos financeiros. Além disso, devem constar, ainda, os critérios e as premissas adotados para a determinação desse valor de mercado, bem como as políticas de atuação e controle das operações nos mercados derivativos e os riscos envolvidos.

Todos os tipos de exposição para os quais são utilizados derivativos - moeda, juros e commodities - foram considerados, destacando-se que os usuários de derivativos de moeda representam a maior parte das firmas da amostra. Constrói-se assim uma variável dummy, que assume o valor 1 caso a firma seja usuária de derivativos; caso contrário, assume o valor 0 (zero).

Constrói-se também uma variável contínua para a utilização de derivativos. Esta é definida como sendo a razão entre o valor nominal do total de derivativos utilizados e o valor do ativo total da firma. Observa-se que, idealmente, o valor total líquido dos derivativos utilizados deveria ser contabilizado, mas tal informação não está disponível para a maioria das firmas. Porém, como a maior parte das firmas assume somente uma posição no mercado de derivativos, a diferença entre as duas variáveis é minimizada. Rossi (2007), por exemplo, mostra que os contratos de swap são os derivativos mais utilizados pelas firmas brasileiras, o que minimizaria o fato de se ter somente o valor total nominal dos derivativos utilizados pela firma.

Para se inferir se a política de proteção tem um impacto sobre o valor da firma, é necessário controlar outras variáveis mencionadas pela literatura, as quais, porventura, possam ter impacto sobre esse valor. Assim, as variáveis de controle utilizadas são:

- Tamanho: A proxy é calculada como o logaritmo do total de ativos das empresas. Seja pelo fato de que empresas maiores tenham maior expertise no gerenciamento de projetos, seja porque atraiam profissionais com melhor capital humano, seja pela existência de um relacionamento positivo entre lucratividade e tamanho, espera-se um relacionamento positivo entre o tamanho e o valor da firma. Além disso, Judge (2003) mostra 
que a expectativa de que as grandes firmas tenham uma probabilidade maior de usar derivativos é confirmada em diversos trabalhos que analisam os determinantes da utilização de derivativos.

- Liquidez: Seguindo o argumento do free cash flow de Jensen (1986), as empresas mais líquidas teriam um Q mais baixo, pois teriam uma probabilidade maior de investir em projetos que apresentassem um VPL negativo. A partir de Pramborg (2004), utilizou-se como proxy da liquidez da firma a variável liquidez corrente definida como a razão entre o ativo e o passivo circulantes da firma.

- Alavancagem: A estrutura de capital da firma também pode estar relacionada ao seu valor. Para controlar as diferenças na estrutura de capital, calcula-se a alavancagem da firma definida pela razão de dívida de longo prazo sobre os ativos totais. O impacto da alavancagem sobre o valor da firma é ambíguo. Se houver tax shields com relação ao pagamentos de juros, o impacto será positivo. Se o aumento da alavancagem representar um aumento da probabilidade de incorrer no pagamento dos custos de falência, seu impacto será negativo.

- Lucratividade: Uma empresa rentável deve ser negociada com prêmio sobre uma menos rentável, portanto espera-se que empresas mais lucrativas tenham um $\mathrm{Q}$ de Tobin mais alto. $\mathrm{O}$ índice de retorno sobre os ativos (ROA), calculado pela razão da receita líquida sobre o total de ativos, é utilizado como proxy para a lucratividade das firmas.

- Oportunidade de investimento: Froot e outros (1993) mostram um relacionamento entre as oportunidades de investimento da firma e as atividades de hedging, relacionamento confirmado empiricamente por Geczy e outros (1997). A razão "investimento calculado pela variação do ativo permanente sobre as vendas totais" é utilizada como indicativa das oportunidades de investimento da firma. Trabalhos empíricos também utilizam a razão de investimentos em pesquisa e desenvolvimento sobre vendas totais como indicação das oportunidades de investimento. Infelizmente, esse dado não está disponível para todas as firmas.

- Diversificação geográfica: Diversas teorias sugerem que as empresas que diversificam geograficamente suas operações apresentam um maior valor de mercado. Morck e Yeung (1991) e Bodnar, Tang e Weintrop (1997) encontraram uma relação positiva entre a diversificação geográfica e o valor da firma. Como vendas externas são vendas de operações fora do país, firmas com vendas externas são multinacionais; então, seguin- do Allayannis e Weston (2001), a razão entre vendas externas e vendas totais é utilizada como proxy para a diversificação geográfica da firma. Espera-se que a multinacionalidade de uma empresa seja positivamente correlacionada ao seu valor. Ademais, o trabalho também utiliza uma variável dummy que assume o valor 1 caso a firma apresente subsidiárias no exterior, e 0 (zero) em caso contrário, como proxy da diversificação geográfica da firma.

- Diversificação industrial: A teoria estabelece um relacionamento ambíguo entre a diversificação da produção em diversos setores e o valor da firma; já a evidência empírica (Berger e Ofek, 1995; Lang e Stulz, 1994) sugere um relacionamento negativo entre o valor da firma e sua diversificação industrial. Seguindo Allayannis, Lel e Miller (2007), constrói-se uma variável dummy que assume o valor 1 se a firma atuar em mais de um setor industrial considerando o nível de desagregação (four-digit SIC level), e 0 (zero) em caso contrário.

- Efeito da indústria: Se empresas que utilizam operações de hedge são concentradas em indústrias com um Q grande, então essas empresas terão maior valor não porque utilizam hedge, mas porque pertencem a um setor industrial específico que possui um $\mathrm{Q}$ alto Utilizaremos dummies setoriais para analisar os efeitos de cada setor no valor da firma.

- Efeitos do tempo: O valor da firma pode ser afetado pela situação macroeconômica do país: restrições ao fluxo de capital internacional, adoção de imposto sobre investidores, mudanças na legislação. Além disso, devido à possibilidade da existência de um relacionamento entre o regime cambial e as atividades de hedging (SCHNEIDER e TORNELL, 2004), faz-se necessário controlar o impacto do ambiente macroeconômico. Dessa maneira, dummies de ano são acrescentadas à estimação com o objetivo de controlar possíveis efeitos macroeconômicos.

A Tabela 1 apresenta o resumo das estatísticas da amostra. O Painel A indica que a amostra tem suficiente variabilidade dentre as firmas. As empresas da amostra apresentam uma média de $\mathrm{R} \$ 2.896$ milhões em ativos, com desvio padrão igual a $\mathrm{R} \$ 10.550$ milhões, indicando que a amostra não está confinada a empresas de grande porte, também havendo empresas médias e pequenas quando comparadas à média. Fato semelhante se observa quando são analisadas as vendas totais e o valor de mercado das firmas como proxies para o tamanho destas. 
Outro fato relevante apresentado pelo Painel A é que o Q de Tobin das firmas tem a média $(0,98)$ superior à mediana $(0,89)$, mostrando uma assimetria em sua distribuição. Fato semelhante foi observado por Allayannis e Weston (2001) e Jin e Jorion (2004). Para minimizar esse problema nas estimações subseqüentes, o logaritmo dessa variável será utilizado quando da implementação econométrica. O Painel B, contido na Tabela 1, apresenta as estatísticas das variáveis de controle. Os resultados contidos no painel também indicam que as variáveis de controle apresentam suficiente variabilidade para controlar as diferenças entre as firmas.

A Tabela 2 mostra a evolução no tempo da utilização de derivativos e a importância da exposição cambial nas empresas brasileiras. Os resultados indicam que a proporção de empresas que utilizam derivativos variou ao longo dos anos. Iniciando em 1996, a fração de empresas na amostra que utilizam derivativos aumentou consistentemente até 2002, período em que atingiu seu ápice. Após 2002, a utilização apresentou uma queda, atingindo $26 \%$ da amostra em 2006.

A tabela também mostra que uma fração superior a 50\% da amostra compõem-se de empresas exportadoras. Além disso, cerca de $80 \%$ mantêm dívida denominada em moeda estrangeira e $20 \%$ apresentam subsidiárias no exterior.
Portanto, os dados contidos na Tabela 2 indicam que a maioria das empresas apresenta alguma fonte de sensibilidade a flutuações na taxa de câmbio. Diferentemente de Allayannis e Weston (2001), as estimações serão realizadas utilizando-se todas as firmas da amostra e não somente as confinadas às empresas exportadoras, dado o alto grau de exposição das empresas brasileiras ao comércio internacional, por outros motivos além de suas vendas externas.

A Tabela 3 traz uma primeira evidência acerca do impacto da utilização de derivativos sobre o valor da firma. Os dados mostram que as empresas que usam derivativos apresentam um Q de Tobin maior que o das empresas que não os utilizam. Com exceção de 1998, o teste-t para igualdade das médias indica que as empresas que utilizam derivativos têm um valor de mercado maior do que as empresas que não utilizam derivativos.

Esta tabela também mostra que o comportamento das firmas brasileiras com relação à utilização de derivativos é consistente com a existência de custos fixos de hedging. Embora o teste para as médias não seja robusto para todos os anos, há uma indicação de que as firmas maiores utilizam mais intensamente os derivativos. O mesmo acontece com as firmas mais lucrativas, firmas com maiores oportunidades de crescimento, com exposição externa,

\section{Tabela 1 - Estatísticas da amostra}

\begin{tabular}{|l|c|c|c|c|c|c|}
\hline \multicolumn{1}{|c|}{ Variável/Estatística } & N & Média & $\begin{array}{c}\text { Desvio } \\
\text { padrão }\end{array}$ & Mediana & $\begin{array}{c}10 \% \\
\text { Percentil }\end{array}$ & $\begin{array}{c}90 \% \\
\text { Percentil }\end{array}$ \\
\hline Ativos totais (R\$ milhões) & 1925 & 2896 & 10550 & 580 & 71 & 5902 \\
\hline Vendas totais (R\$ milhões) & 1925 & 2328 & 9546 & 506 & 47 & 4803 \\
\hline Valor de mercado (R\$ milhões) & 1925 & 1833 & 9622 & 144 & 8 & 3116 \\
\hline Q de Tobin & 1925 & 0,98 & 0,47 & 0,89 & 0,57 & 1,43 \\
\hline & & PAINEL B - CONTROLES & & & \\
\hline Lucratividade (\%) & 1925 & $8,69 \%$ & $7,01 \%$ & $7,52 \%$ & $2,80 \%$ & $14,30 \%$ \\
\hline Crescimento (\%) & 1925 & $-0,68 \%$ & $15,9 \%$ & $-0,27 \%$ & $-0,62 \%$ & $33,2 \%$ \\
\hline Alavancagem (\%) & 1925 & $11,6 \%$ & $11,6 \%$ & $8,96 \%$ & $0,00 \%$ & $27,4 \%$ \\
\hline Liquidez & 1925 & 1,55 & 1,08 & 1,33 & 0,60 & 2,71 \\
\hline Diversificação industrial & 1925 & 0,17 & 0,38 & 0 & 0 & 1 \\
\hline Diversificação geográfica & 1925 & $14,9 \%$ & $20,9 \%$ & $5,80 \%$ & $0,00 \%$ & $44,2 \%$ \\
\hline
\end{tabular}

Nota: A Tabela 1 apresenta as estatísticas da amostra. 0 Painel A mostra um resumo das estatísticas de algumas variáveis do estudo. 0 Painel B mostra as estatísticas das variáveis de controle utilizadas na análise. 
Tabela 2 - Exposição cambial

\begin{tabular}{|l|l|l|l|l|l|l|l|l|l|}
\hline & 1996 & 1997 & 1998 & 1999 & 2000 & 2001 & 2002 & 2003 & 2004 \\
\hline $\begin{array}{l}\text { Número de } \\
\text { empresas }\end{array}$ & 175 & 175 & 175 & 175 & 175 & 175 & 175 & 175 & 175 \\
\hline
\end{tabular}

Nota: A Tabela 2 apresenta algumas variáveis indicativas da importância da exposição cambial na amostra.

Tabela 3 - Características dos usuários de derivativos

\begin{tabular}{|c|c|c|c|c|c|c|c|c|c|c|c|c|}
\hline & & 1996 & 1997 & 1998 & 1999 & 2000 & 2001 & 2002 & 2003 & 2004 & 2005 & 2006 \\
\hline \multirow{2}{*}{ Q de Tobin } & Usuário & $1,07^{*}$ & $0,91 *$ & 0,77 & $1,11^{* *}$ & $1,13^{*}$ & $0,96 *$ & $1,00 *$ & $1,20 *$ & $1,41^{*}$ & $1,37^{*}$ & $1,53^{*}$ \\
\hline & Não & 0,81 & 0,82 & 0,75 & 0,90 & 0,84 & 0,84 & 0,87 & 0,94 & 1,08 & 1,10 & 1,27 \\
\hline \multirow{2}{*}{$\begin{array}{l}\text { Tamanho } \\
\text { (R\$ milhões) }\end{array}$} & Usuário & 1677 & $2143^{* *}$ & $2500^{*}$ & $2578 * *$ & $2926 *$ & 2952 & 3460 & $4143^{*}$ & $5123^{*}$ & $5430 *$ & $7148^{*}$ \\
\hline & Não & 1400 & 1499 & 1638 & 1958 & 1951 & 2200 & 2827 & 3184 & 3378 & 4130 & 5188 \\
\hline \multirow{2}{*}{$\begin{array}{l}\text { Lucratividade } \\
\text { (\%) }\end{array}$} & Usuário & $8,84 \%$ & $8,12 \%$ & $8,21 \%$ & $10,0 \%$ & $9,56 \%$ & $9,42 \%$ & $9,35 \%$ & $11,2 \% *$ & $12,1 \% * *$ & $11,6 \%$ & $9,97 \%$ \\
\hline & Não & $7,91 \%$ & $7,93 \%$ & $7,44 \%$ & $7,22 \%$ & $7,88 \%$ & $7,93 \%$ & $7,94 \%$ & $8,50 \%$ & $9,21 \%$ & $9,32 \%$ & $9,72 \%$ \\
\hline \multirow{2}{*}{ Liquidez } & Usuário & 1,27 & 1,34 & 1,37 & 1,53 & 1,40 & 1,17 & 1,23 & 1,29 & 1,34 & 1,46 & 1,60 \\
\hline & Não & 1,40 & 1,40 & 1,34 & 1,34 & 1,40 & 1,51 & 1,41 & 1,47 & 1,52 & 1,56 & 1,65 \\
\hline \multirow{2}{*}{$\begin{array}{l}\text { Oportunidade } \\
\text { de investimen- } \\
\text { to }(\%)\end{array}$} & Usuário & $1,50 \% *$ & $0,04 \% * *$ & $0,25 \% *$ & $-5,44 \%$ & $-0,26 \%$ & $3,94 \% *$ & $-0,05 \%$ & $0,64 \%$ & $1,22 \%$ & $0,84 \%$ & $1,02 \%$ \\
\hline & Não & $-6,60 \%$ & $-0,25 \%$ & $-1,70 \%$ & $-0,18 \%$ & $-0,59 \%$ & $-0,98 \%$ & $-5,02 \%$ & $-0,53 \%$ & $0,94 \%$ & $-1,06 \%$ & $-0,72 \%$ \\
\hline \multirow{2}{*}{$\begin{array}{l}\text { Vendas externas } \\
\text { / Vendas totais }\end{array}$} & Usuário & $23,7 \% *$ & $17,0 \%$ & $18,8 \% *$ & $18,8 \% *$ & $15,9 \%$ & $19,1 \%$ & $21,1 \% *$ & $17,7 \%$ & $19,2 \% * *$ & $18,9 \% *$ & $19,7 \% *$ \\
\hline & Não & $11,3 \%$ & $11,7 \%$ & $13,7 \%$ & $13,7 \%$ & $14,3 \%$ & $13,5 \%$ & $13,7 \%$ & $16,0 \%$ & $15,6 \%$ & $14,5 \%$ & $14,1 \%$ \\
\hline \multirow{2}{*}{$\begin{array}{l}\text { Alavancagem } \\
\text { (\%) }\end{array}$} & Usuário & $12,1 \% *$ & $16,6 \% *$ & $18,0 \% *$ & $17,6 \% *$ & $15,5 \% *$ & $17,7 \% *$ & $16,6 \% *$ & $16,6 \% *$ & $14,0 \% *$ & $14,4 \% *$ & $14,9 \% *$ \\
\hline & Não & $9,33 \%$ & $10,8 \%$ & $10,4 \%$ & $11,7 \%$ & $10,9 \%$ & $10,4 \%$ & $10,5 \%$ & $8,86 \%$ & $8,33 \%$ & $8,56 \%$ & $9,89 \%$ \\
\hline \multirow{2}{*}{$\begin{array}{l}\text { Dívida em moe- } \\
\text { da estrangeira / } \\
\text { Dívida total (\%) }\end{array}$} & Usuário & $70,4 \% *$ & $74,3 \% *$ & $68,0 \% *$ & $72,1 \% *$ & $69,8 \% *$ & $70,0 \% *$ & $67,9 \% *$ & $64,5 \% *$ & $62,6 \% *$ & $54,1 \% *$ & $45,4 \% *$ \\
\hline & Não & $42,8 \%$ & $43,8 \%$ & $43,1 \%$ & $45,2 \%$ & $41,4 \%$ & $37,4 \%$ & $36,3 \%$ & $30,0 \%$ & $30,8 \%$ & $26,2 \%$ & $26,0 \%$ \\
\hline
\end{tabular}

Nota: A Tabela 3 examina as características das empresas usuárias de derivativos. Nesta tabela, *, ** indicam, respectivamente, a rejeição a $5 \%$ e $10 \%$ da igualdade das médias por meio de um teste $t$. 
devido à receita obtida no exterior e dívida denominada em moeda estrangeira e com maior probabilidade de incorrer no pagamento de custos de falência, mostrado pelo relacionamento positivo entre alavancagem e a utilização de derivativos.

\section{METODOLOGIA}

O objetivo da análise é testar se o uso de derivativos tem um impacto positivo sobre o valor da firma. Inicialmente, a seguinte equação é estimada para o período de 1996 a 2006:

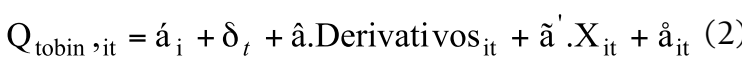

Em que $\mathrm{Q}_{\text {tobin,it }}$ representa o $\mathrm{Q}$ de Tobin de cada firma $\mathrm{i}$ no período t, $\mathrm{X}_{\mathrm{it}}$ é o conjunto de variáveis de controle mencionadas anteriormente e â o coeficiente de interesse, pois indica o impacto da utilização de derivativos sobre o valor da firma.

São utilizadas duas proxies para a utilização de derivativos. A primeira, denominada uso de derivativos, é uma variável dummy que assume o valor 1 se a firma utilizou derivativos no período te 0 em caso contrário. A segunda variável é a razão entre o valor total nominal dos derivativos usados pela firma normalizado pelo valor dos ativos totais da firma.

Inicialmente, a equação (2) foi estimada em crosssection (pooled-OLS) e em um painel com efeitos individuais, com o intuito de verificar a robustez dos resultados aos diferentes métodos de estimação e comparação com os resultados existentes na literatura. $\delta_{t}$ representa as dummies temporais também incluídas nas regressões, com o objetivo de controlar os efeitos macroeconômicos em cada ano da amostra. Na estimação em cross-section, dummies setoriais também são incluídas com o intuito de controlar as diferenças entre os diversos setores.

Um problema mencionado na literatura para a estimação da equação (2) é a possibilidade de uma causalidade reversa entre a utilização de derivativos e o $\mathrm{Q}$ de Tobin. Se um Q de Tobin alto reflete o fato de que a firma tem maiores oportunidades de investimento, então, como predito pela teoria do hedging ótimo, essa terá mais incentivos para realizar atividades de hedging. Dessa maneira, o relacionamento positivo refletiria o fato de que empresas com maiores oportunidades de crescimento teriam um incentivo a utilizar derivativos, não que a utilização de de- rivativos levaria a valores mais altos do valor da firma.

Para tratar desse problema, também se estima equação (2) por meio de uma regressão com a utilização de variáveis instrumentais. Trata-se de uma estimação em dois estágios. No primeiro estágio, a equação (1) é estimada para a determinação da utilização de derivativos. Na segunda etapa, a equação (2) é estimada com os valores preditos pela primeira etapa. O problema de uma estimação com variáveis instrumentais é que bons instrumentos são necessários, caso contrário a estimação por OLS geraria resultados superiores.

A literatura acerca dos determinantes da utilização de derivativos nos fornece possíveis instrumentos para a estimação de (2), já que estas variáveis seriam correlacionadas com a utilização de derivativos, mas não com o valor da firma, característica de um instrumento válido. Smith e Stulz (1985) argumentam que as firmas utilizam derivativos para reduzir o pagamento esperado de impostos. É usada, então, a razão entre os impostos diferidos e os ativos totais como proxy da taxação usada como instrumento para a estimação de (2). Devido ao fato de a variável 'uso de derivativos' ser uma variável discreta, a estimação por variáveis instrumentais somente é realizada utilizando-se a variável contínua, calculada pela razão entre o valor dos derivativos e os ativos totais.

Partindo dos métodos utilizados na literatura existente, o estudo propõe um método não-paramétrico para a estimação do impacto da utilização de derivativos sobre o valor da firma. No propensity score matching é formulada a seguinte questão contrafactual: Qual seria a diferença entre o valor de duas firmas, caso a única diferença entre elas fosse a utilização de derivativos? Inicialmente, é calculada a probabilidade de a empresa utilizar derivativos, dado o conjunto de variáveis de seleção. Portanto, primeiramente, um modelo probit para a determinação da utilização de derivativos é estimado. Então, para cada empresa que usa derivativos, é encontrada outra empresa que não utilizou derivativos, cuja probabilidade (propensity score) de usar derivativos, dadas as variáveis de controle, seja a mais próxima possível. Por fim, para todo o conjunto de empresas, compara-se o valor da firma entre a empresa que utilizou derivativos e a mais próxima que não os utilizou. Como variáveis de seleção, são utilizadas as mesmas das estimações anteriores, acrescidas da razão de dívida em moeda estrangeira sobre a dívida total. Esta foi acrescida devido ao fato de Rossi (2007) e Saito e Schiozer (2007) mostrarem tal variável como sendo um dos principais determinantes da utilização de derivativos por firmas brasileiras. 


\section{RESULTADOS}

Os resultados da estimação da equação (2) encontram-se na Tabela 4. Eles confirmam que a utilização de derivativos tem um impacto positivo e significativo sobre o valor da firma, sendo consistentes com Allayannis e Weston (2001) e Hagelin e outros (2004), que verificaram que a utilização de derivativos de moedas possui uma relação positiva com o valor da firma para empresas norte-americanas e suecas.

Interessante observar que a estimação por pooled OLS indica um hedging premium de 9,8\%, ou seja, mantido tudo mais igual, as firmas que usam derivativos têm um valor 9,8\% maior do que as firmas que não os utilizam. Esse resultado é superior ao verificado por Allayanis e Weston (2001), que encontraram um prêmio de cerca de 5\% para empresas norte-americanas que usam derivativos, valor esse estimado por método econométrico semelhante. Já as estimações por painel indicam um prêmio de cerca de $3,7 \%$ para as empresas que utilizam derivativos.

Os resultados são robustos com relação à variável proxy para a utilização de derivativos e ao possível problema de endogeneidade na estimação. Os resultados contidos na Tabela 4 indicam que, caso a razão derivativos sobre ativos totais seja usada como proxy para a utilização de derivativos, o coeficiente continua positivo e estatisticamente significante. O mesmo acontece quando a equação (2) é estimada pelo método de variáveis instrumentais.

Tabela 4 - Resultados da estimação

\begin{tabular}{|l|c|c|c|c|c|c|}
\hline & POLLE & PAINEL & POLLE & PAINEL & POLLED - IV & PAINEL - IV \\
\hline Uso de derivativos & 0,098 & 0,037 & & \\
\hline & $(4,80)^{*}$ & $(1,72)^{*}$ & & & \\
\hline
\end{tabular}

Nota: A Tabela 4 mostra o resultado da estimação da equação (2) por meio de diferentes métodos econométricos. *,** indicam, respectivamente, significância a 5\% e 10\%. Estatística-t entre parêntesis. 
Com relação às variáveis de controle, observa-se que existe um relacionamento positivo entre o tamanho e o valor da firma. Os resultados confirmam que firmas mais líquidas apresentam Qs mais baixos, o que é indicado pelo relacionamento negativo entre liquidez e o valor da firma. Os resultados contidos na Tabela 4 indicam que firmas mais alavancadas apresentam um maior valor, confirmando as teorias do monitoramento exercido pela dívida ou a importância de tax shields, embora esse resultado não seja robusto nas diferentes especificações.

Os resultados apresentados na Tabela 4 também confirmam que firmas mais lucrativas apresentam Qs mais altos, indicado pelo coeficiente positivo e significativo da proxy de lucratividade. Confirmando as expectativas, tanto as oportunidades de investimento das firmas quanto sua diversidade industrial exercem um impacto positivo sobre o valor da firma, embora o último resultado não seja robusto nas diferentes especificações. Já a diversidade geográfica, quando representada pela razão entre as vendas externas sobre as vendas totais, embora traga o sinal esperado, não apresenta um impacto estatisticamente significante. Ao contrário, quando se utiliza a variável indicativa da existência de subsidiárias no exterior, há a indicação de um impacto positivo da multinacionalidade da firma sobre o seu valor.

Os resultados obtidos pelo método de propensity score matching são encontrados na Tabela 5. O painel A apresenta os resultado da estimação de um modelo probit para a probabilidade de utilizar derivativos e o painel B apresenta o resultado da comparação entre os Qs de Tobin dos dois grupos de empresas.

Inicialmente, o método foi implementado para o período completo da amostra - 1996 a 2006. Os resultados indicam que firmas maiores, mais alavancadas, mais lucrativas, com maior diversidade industrial, maior razão de vendas externas sobre vendas totais e dívida denominada em moeda estrangeira sobre a dívida total apresentam uma probabilidade maior de utilizar derivativos. Por outro lado, firmas com subsidiárias no exterior apresentam um probabilidade menor de usar derivativos, provavelmente indicando que as firmas percebem hedges operacionais como substitutos de hedges financeiros.

Os resultados contidos no Painel B confirmam que, no período de 1996 a 2006, as empresas usuárias de derivativos apresentaram um Q mais alto $(1,171)$ do que as firmas não usuárias de derivativos $(0,915)$. A diferença $(0,256)$ é positiva e estatisticamente significante, confirmando, assim, os resultados anteriores de que a utilização de derivativos tem um impacto positivo e significativo sobre o valor da firma.
Os resultados apresentados na Tabela 5, quando o método é aplicado em cada ano da amostra, indicam que, embora a significância das variáveis de seleção mude de ano para ano, com exceção dos anos de 1997 e 1998, em todos os outros anos da amostra a diferença entre o Q de Tobin de empresas usuárias de derivativos e o de nãousuárias mostrou-se positiva e estatisticamente significativa, confirmando a robustez dos resultados encontrados Interessante observar que a diferença de valor entre as empresas usuárias e as não-usuárias de derivativos aumentou tanto após a crise cambial de 1999 quanto em 2002, indicando que, após momentos de crise, o mercado mostra-se disposto a pagar um prêmio por uma política ativa de proteção da firma.

\section{ROBUSTEZ DOS RESULTADOS}

Um dos possíveis problemas na estimação da equação (2) é a definição da variável dependente - Q de Tobin. Famá e Barros (2000) discutem as diversas maneiras de se calcular o Q de Tobin. Nos resultados anteriores, optou-se por uma metodologia semelhante à de Pramborg (2004), Allayannis, Lel e Miller (2007), dentre outros. Como exercício de robustez, a equação (2) foi estimada utilizando duas metodologias alternativas para o cálculo do Q de Tobin. Chung e Pruitt (1994) definem a variável como:

$$
Q 2=\frac{V M A+V C P C-V C A C+V C E+V C D L P}{A T}
$$

Onde VMA é o valor de mercado da firma, VCPC é o valor contábil do passivo circulante da firma, VCAC representa o ativo circulante, VCE é o valor contábil dos estoques e VCDLP é o valor contábil da dívida de longo prazo. Finalmente, AT indica o ativo total das firmas.

Já Shin e Stulz (2000) utilizam a seguinte definição para o Q de Tobin:

$$
Q 3=\frac{V M A+V C D}{A T}
$$

Em que novamente VMA representa o valor de mercado da firma e AT o valor do ativo total. Já VCD é o valor contábil das dívidas. A Tabela 6 mostra a correlação entre as diferentes proxies do $\mathrm{Q}$ de Tobin. Os resultados indicam que o $\mathrm{Q}$ de Tobin calculado por (1) é altamente correlacionado com a variável calculada utilizando a equação (3). Já o valor do $\mathrm{Q}$ de Tobin calculado por (4) apresentou uma correlação mais baixa com relação às outras proxies para o $\mathrm{Q}$ de Tobin. 
Tabela 5 - Propensity Score Matching

\begin{tabular}{|c|c|c|c|c|c|c|c|c|c|c|c|c|}
\hline $\begin{array}{l}\text { Características } \\
\text { das empresas }\end{array}$ & $\begin{array}{l}1996 \\
-2006\end{array}$ & 1996 & 1997 & 1998 & 1999 & 2000 & 2001 & 2002 & 2003 & 2004 & 2005 & 2006 \\
\hline Tamanho & $\begin{array}{c}0,154 \\
(5,99)^{*}\end{array}$ & $\begin{array}{l}0,210 \\
(1,37)\end{array}$ & $\begin{array}{l}0,136 \\
(1,01)\end{array}$ & $\begin{array}{l}0,063 \\
(0,51)\end{array}$ & $\begin{array}{l}0,190 \\
(1,52)\end{array}$ & $\begin{array}{c}0,253 \\
(2,35)^{*}\end{array}$ & $\begin{array}{l}0,157 \\
(1,50)\end{array}$ & $\begin{array}{l}0,132 \\
(1,27)\end{array}$ & $\begin{array}{l}0,130 \\
(1,08)\end{array}$ & $\begin{array}{c}0,267 \\
(2,35)^{*}\end{array}$ & $\begin{array}{c}0,307 \\
(2,80)^{*}\end{array}$ & $\begin{array}{c}0,349 \\
(3,15)^{*}\end{array}$ \\
\hline Alavancagem & $\begin{array}{c}0,984 \\
(2,92)^{*}\end{array}$ & $\begin{array}{l}0,432 \\
(0,24)\end{array}$ & $\begin{array}{l}2,387 \\
(1,37)\end{array}$ & $\begin{array}{c}3,940 \\
(2,73)^{*}\end{array}$ & $\begin{array}{c}2,640 \\
(2,15)^{*}\end{array}$ & $\begin{array}{l}0,482 \\
(0,47)\end{array}$ & $\begin{array}{l}0,255 \\
(0,29)\end{array}$ & $\begin{array}{l}0,310 \\
(0,34)\end{array}$ & $\begin{array}{l}1,058 \\
(1,01)\end{array}$ & $\begin{array}{l}0,847 \\
(0,67)\end{array}$ & $\begin{array}{l}2,035 \\
(1,52)\end{array}$ & $\begin{array}{l}0,632 \\
(0,46)\end{array}$ \\
\hline Lucratividade & $\begin{array}{c}0,401 \\
(6,16)^{*}\end{array}$ & $\begin{array}{c}0,569 \\
(2,00)^{*}\end{array}$ & $\begin{array}{c}0,419 \\
(1,71)^{* *}\end{array}$ & $\begin{array}{c}0,553 \\
(2,15)^{*}\end{array}$ & $\begin{array}{c}1,055 \\
(3,11)^{*}\end{array}$ & $\begin{array}{c}0,547 \\
(1,99)^{*}\end{array}$ & $\begin{array}{c}0,525 \\
(1,91)^{* *}\end{array}$ & $\begin{array}{c}0,421 \\
(1,84)^{* *}\end{array}$ & $\begin{array}{c}0,547 \\
(1,93)^{* *}\end{array}$ & $\begin{array}{c}0,587 \\
(2,22)^{*}\end{array}$ & $\begin{array}{c}0,497 \\
(1,97)^{*}\end{array}$ & $\begin{array}{l}0,045 \\
(0,34)\end{array}$ \\
\hline Liquidez & $\begin{array}{l}-0,045 \\
(-0,90)\end{array}$ & $\begin{array}{l}0,108 \\
(0,41)\end{array}$ & $\begin{array}{l}-0,006 \\
(-0,01)\end{array}$ & $\begin{array}{l}0,112 \\
(0,68)\end{array}$ & $\begin{array}{c}0,251 \\
(1,71)^{* *}\end{array}$ & $\begin{array}{l}0,015 \\
(0,12)\end{array}$ & $\begin{array}{c}-0,352 \\
(-1,88)^{* *}\end{array}$ & $\begin{array}{l}-0,150 \\
(-0,97)\end{array}$ & $\begin{array}{l}-0,144 \\
(-0,79)\end{array}$ & $\begin{array}{l}-0,291 \\
(-1,36)\end{array}$ & $\begin{array}{l}0,045 \\
(0,35)\end{array}$ & $\begin{array}{l}-0,074 \\
(-0,41)\end{array}$ \\
\hline $\begin{array}{l}\text { Oportuni- } \\
\text { dade de } \\
\text { investimento }\end{array}$ & $\begin{array}{l}0,012 \\
(0,89)\end{array}$ & $\begin{array}{l}-0,015 \\
(-0,26)\end{array}$ & $\begin{array}{l}0,022 \\
(0,81)\end{array}$ & $\begin{array}{l}-0,023 \\
(-1,07)\end{array}$ & $\begin{array}{l}0,093 \\
(0,15)\end{array}$ & $\begin{array}{l}0,026 \\
(0,60)\end{array}$ & $\begin{array}{l}0,048 \\
(0,51)\end{array}$ & $\begin{array}{l}0,085 \\
(0,80)\end{array}$ & $\begin{array}{l}0,148 \\
(1,16)\end{array}$ & $\begin{array}{l}0,088 \\
(0,26)\end{array}$ & $\begin{array}{l}0,152 \\
(0,39)\end{array}$ & $\begin{array}{l}0,064 \\
(0,43)\end{array}$ \\
\hline $\begin{array}{l}\text { Diversificação } \\
\text { industrial }\end{array}$ & $\begin{array}{c}0,54 \\
(5,07)^{*}\end{array}$ & $\begin{array}{c}0,77 \\
(1,61)\end{array}$ & $\begin{array}{c}0,72 \\
(1,67)^{* *}\end{array}$ & $\begin{array}{c}1,09 \\
(2,75)^{*}\end{array}$ & $\begin{array}{c}0,82 \\
(2,08)^{*}\end{array}$ & $\begin{array}{c}0,61 \\
(1,80)^{* *}\end{array}$ & $\begin{array}{l}0,523 \\
(1,51)\end{array}$ & $\begin{array}{l}0,411 \\
(1,21)\end{array}$ & $\begin{array}{l}0,380 \\
(1,05)\end{array}$ & $\begin{array}{l}0,410 \\
(1,16)\end{array}$ & $\begin{array}{l}0,455 \\
(1,24)\end{array}$ & $\begin{array}{l}0,157 \\
(0,44)\end{array}$ \\
\hline $\begin{array}{l}\text { Diversificação } \\
\text { geográfica }\end{array}$ & $\begin{array}{c}0,337 \\
(1,81)^{* *}\end{array}$ & $\begin{array}{c}1,312 \\
(1,88)^{* *}\end{array}$ & $\begin{array}{l}1,035 \\
(1,47)\end{array}$ & $\begin{array}{l}0,818 \\
(1,25)\end{array}$ & $\begin{array}{l}0,972 \\
(1,60)\end{array}$ & $\begin{array}{l}0,100 \\
(0,16)\end{array}$ & $\begin{array}{l}0,452 \\
(0,73)\end{array}$ & $\begin{array}{l}-0,026 \\
(-0,05)\end{array}$ & $\begin{array}{l}-0,550 \\
(-0,88)\end{array}$ & $\begin{array}{l}0,181 \\
(0,28)\end{array}$ & $\begin{array}{l}0,183 \\
(0,27)\end{array}$ & $\begin{array}{l}0,334 \\
(0,47)\end{array}$ \\
\hline $\begin{array}{l}\text { Subsidiárias } \\
\text { no exterior }\end{array}$ & $\begin{array}{c}-0,196 \\
(-1,94)^{* *}\end{array}$ & $\begin{array}{r}-0,457 \\
(-0,96)\end{array}$ & $\begin{array}{l}0,024 \\
(0,06)\end{array}$ & $\begin{array}{l}-0,271 \\
(-0,73)\end{array}$ & $\begin{array}{l}-0,414 \\
(-1,16)\end{array}$ & $\begin{array}{c}-0,64 \\
(-1,89)^{*}\end{array}$ & $\begin{array}{l}-0,238 \\
(-0,72)\end{array}$ & $\begin{array}{l}0,007 \\
(0,02)\end{array}$ & $\begin{array}{l}-0,199 \\
(-0,61)\end{array}$ & $\begin{array}{l}-0,258 \\
(-0,77)\end{array}$ & $\begin{array}{l}-0,241 \\
(-0,72)\end{array}$ & $\begin{array}{l}0,228 \\
(0,69)\end{array}$ \\
\hline $\begin{array}{l}\text { Dívida em } \\
\text { moeda est. / } \\
\text { Dívida total }\end{array}$ & $\begin{array}{c}1,00 \\
(7,05)^{*}\end{array}$ & $\begin{array}{l}1.032 \\
(1,53)\end{array}$ & $\begin{array}{c}1,326 \\
(2,05)^{*}\end{array}$ & $\begin{array}{c}0,915 \\
(1,71)^{* *}\end{array}$ & $\begin{array}{c}0,990 \\
(1,93)^{* *}\end{array}$ & $\begin{array}{c}1,182 \\
(2,51)^{*}\end{array}$ & $\begin{array}{c}1,330 \\
(2,75)^{*}\end{array}$ & $\begin{array}{c}1,502 \\
(3,26)^{*}\end{array}$ & $\begin{array}{c}1,813 \\
(3,57)^{*}\end{array}$ & $\begin{array}{c}1,429 \\
(2,99)^{*}\end{array}$ & $\begin{array}{l}0,559 \\
(1,32)\end{array}$ & $\begin{array}{l}-0,206 \\
(-0,42)\end{array}$ \\
\hline $\begin{array}{l}\text { Dummies } \\
\text { setoriais }\end{array}$ & Sim & Sim & Sim & Sim & Sim & Sim & Sim & Sim & Sim & Sim & Sim & Sim \\
\hline$N$ & 1925 & 175 & 175 & 175 & 175 & 175 & 175 & 175 & 175 & 175 & 175 & 175 \\
\hline Pseudo-R2 & 0,266 & 0,212 & 0,248 & 0,280 & 0,255 & 0,234 & 0,250 & 0,232 & 0,293 & 0,286 & 0,287 & 0,184 \\
\hline
\end{tabular}

PAINEL B - PROPENSITY SCORE MATCHING

\begin{tabular}{|l|c|c|c|c|c|c|c|c|c|c|c|c|}
\hline Matchings & 657 & 12 & 15 & 24 & 27 & 43 & 57 & 65 & 60 & 56 & 57 & 41 \\
\hline Usuários & 1,171 & 1,076 & 0,909 & 0,756 & 1,114 & 1,125 & 0,956 & 1,002 & 1,197 & 1,415 & 1,378 & 1,532 \\
\hline Não-usuários & 0,915 & 0,809 & 0,823 & 0,770 & 0,902 & 0,847 & 0,850 & 0,862 & 0,944 & 1,088 & 1,107 & 1,298 \\
\hline Diferença & $0,256 *$ & $0,267 *$ & 0,087 & $-0,014$ & $0,211^{* *}$ & $0,278 *$ & $0,105 *$ & $0,140 *$ & $0,253^{*}$ & $0,326 *$ & $0,270 *$ & $0,234 * *$ \\
\hline Desvio padrão & 0,025 & 0,103 & 0,084 & 0,073 & 0,111 & 0,069 & 0,048 & 0,052 & 0,063 & 0,091 & 0,095 & 0,129 \\
\hline (estatística t) & $(10,00)$ & $(2,58)$ & $(1,03)$ & $(-0,19)$ & $(1,89)$ & $(4,03)$ & $(2,16)$ & $(2,70)$ & $(3,96)$ & $(3,58)$ & $(2,83)$ & $(1,81)$ \\
\hline
\end{tabular}

Nota: A Tabela 5 mostra o resultado da estimação não-paramétrica da diferença entre o Q de Tobin de firmas usuárias ou não de derivativos. O Painel A mostra a estimação da probabilidade de a firma utilizar derivativos pela estimação de um modelo PROBIT. O Painel B mostra o resultado da comparação entre os usuários e não usuários. *,** indicam, respectivamente, significância a 5\% e $10 \%$. Estatística-t entre parêntesis. 
Interessante observar que ambas as medidas apresentam uma média inferior a 1 , uma indicação de que a variável inicialmente utilizada seria uma proxy mais adequada.
Os resultados encontrados na Tabela 7 confirmam a robustez da análise anterior. Excetuando a estimação em painel utilizando a variável Q3 como proxy para o Q de

Tabela 6 - Comparação Q de Tobin

\begin{tabular}{|c|c|c|c|c|c|c|}
\hline VARIÁVEL & Q1 & Q2 & Q3 & MÉDIA & $\begin{array}{c}\text { DESVIO } \\
\text { PADRÃO }\end{array}$ & MEDIANA \\
\hline Q1 & 1,0000 & & & 0,98 & 0,47 & 0,89 \\
\hline Q2 & $0,9552^{*}$ & 1,0000 & & 0,41 & 0,48 & 0,33 \\
\hline Q3 & $0,4925 *$ & $0,6576 *$ & 1,0000 & 0,21 & 0,49 & 0,14 \\
\hline
\end{tabular}

Nota: A Tabela 6 mostra a comparação entre os diferentes métodos para o cálculo do Q de Tobin. Q1 representa a variável calculada por meio da equação (1). Q2 e Q3 representam, respectivamente, o Q de Tobin calculado pelas equações (3) e (4). * indica significância estatística a $5 \%$.

Tabela 7 - Resultados com Qs alternativos

\begin{tabular}{|c|c|c|c|c|}
\hline & \multicolumn{2}{|c|}{ Q2 } & \multicolumn{2}{|c|}{ Q3 } \\
\hline & POLLED & PAINEL & POLLED & PAINEL \\
\hline Uso de derivativos & $0,107(3,59)^{*}$ & $0,032(2,33)^{*}$ & $0,112(2,95)^{*}$ & $0,015(0,46)$ \\
\hline Tamanho & $0,033(2,04)^{*}$ & $0,261(6,12)^{*}$ & $0,137(1,87)^{* *}$ & $0,024(1,43)$ \\
\hline Alavancagem & $0,422(3,80)^{*}$ & $0,329(0,96)$ & $0,669(2,19)^{*}$ & $0,290(2,54)^{*}$ \\
\hline Lucratividade & $0,887(0,24)$ & $0,557(7,86)^{*}$ & $0,227(1.09)$ & $0,099(3,84)^{*}$ \\
\hline Liquidez & $-0,011(-3,93) *$ & $-0,020(-0,53)$ & $-0,035(-3,67)^{*}$ & $-0,057(-0,05)$ \\
\hline Oportunidade de investimento & $0,053(1,17)$ & $0,025(1,40)$ & $0,091(1,75)^{* *}$ & $0,023(3,90)^{*}$ \\
\hline Diversificação industrial & $0,234(4,62)^{*}$ & $0,526(3,52)^{*}$ & $0,486(2,86)^{*}$ & $0,205(3,75)^{*}$ \\
\hline Diversificação geográfica & $0,027(2,54)^{*}$ & $0,055(1,90)^{* *}$ & $0,075(2,77)^{*}$ & $0,022(2,19)^{*}$ \\
\hline Subsidiárias no exterior & $0,075(0,25)$ & $0,114(0,66)$ & $0,103(1,48)$ & $0,129(1,75)^{* *}$ \\
\hline Dummies anuais & Sim & Sim & Sim & Sim \\
\hline Dummies setoriais & Sim & Não & Sim & Não \\
\hline $\mathrm{N}$ & 1925 & 1925 & 1925 & 1925 \\
\hline $\mathrm{R} 2$ & 0,271 & 0,153 & 0,237 & 0,105 \\
\hline Matchings & \multicolumn{2}{|c|}{459} & \multicolumn{2}{|c|}{459} \\
\hline Usuários & \multicolumn{2}{|c|}{0,608} & \multicolumn{2}{|c|}{0,413} \\
\hline Não-usuários & \multicolumn{2}{|c|}{0,345} & \multicolumn{2}{|c|}{0,157} \\
\hline Diferença & \multicolumn{2}{|c|}{$0,262 *$} & \multicolumn{2}{|c|}{$0,255^{*}$} \\
\hline $\begin{array}{l}\text { Desvio padrão } \\
\text { (estatística t) }\end{array}$ & \multicolumn{2}{|c|}{$\begin{array}{c}0,026 \\
(10,01)\end{array}$} & \multicolumn{2}{|c|}{$\begin{array}{l}0,027 \\
(9,22)\end{array}$} \\
\hline
\end{tabular}

Nota: A Tabela 7 mostra o resultado da estimação da equação (2) utilizando diferentes métodos para o cálculo do Q de Tobin. *,** indicam, respectivamente, significância a 5\% e 10\%. Estatística-t entre parêntesis. 
Tobin, em todas as especificações a utilização de derivativos apresentou um impacto positivo e estatisticamente significativo sobre o valor da firma. Esse resultado é confirmado pelo método não-paramétrico do matching, que indica uma diferença positiva e significativa entre o $Q$ de Tobin de empresas usuárias e o das não-usuárias de derivativos independentemente da proxy utilizada para o $\mathrm{Q}$ de Tobin. Ademais, embora não sejam significativos em todas as especificações, os resultados sugerem que fatores como tamanho, alavancagem, liquidez, lucratividade, oportunidades de investimento e diversificação industrial e geográfica também exercem um impacto sobre o valor da firma.

\section{CONCLUSÃO}

Este trabalho analisou o uso de derivativos e seu impacto sobre o valor da firma para uma amostra de empresas brasileiras não-financeiras de capital aberto no período de 1996 a 2006. Inicialmente, utilizando métodos econométricos similares aos de trabalhos precedentes para países desenvolvidos, confirmou-se que a utilização de derivativos exerce um impacto positivo e estatisticamente significativo sobre o valor da firma. Foi encontrada evidência de um prêmio pela utilização de derivativos de até $10 \%$ sobre o valor da firma para empresas brasileiras. Prêmio superior ao encontrado por Allayannis e Weston (2001) para os EUA, indicando que, em um ambiente mais volátil, como o Brasil, práticas de proteção são mais remuneradas pelos investidores.

Os resultados se mostraram robustos com relação ao método de análise e proxy para o valor da firma. Utilizando o método não-paramétrico de propensity score matching, o trabalho confirma o impacto positivo que a utilização de derivativos exerce sobre o valor da firma. Os resultados indicam que, após momentos de crise na economia brasileira, como em 1999 e 2002, há um aumento da diferença entre o valor das firmas usuárias e o das não-usuárias de derivativos, comprovando que os investidores estariam dispostos a pagar um prêmio por uma menor volatilidade do fluxo de caixa das empresas.

Modigliani e Miller (1958) concluem em seu clássico trabalho que a política financeira da empresa seria irrelevante em afetar seu valor. Os resultados apresentados indicam que alguma (ou várias) das hipóteses adotadas pelos autores não é (são) válida(s) já que a política de utilização de derivativos exerce um impacto sobre o valor da firma, contrariando, assim, as conclusões desse clássico trabalho.
Pesquisas futuras sobre o impacto da política financeira sobre o valor das firmas podem trabalhar com o fato de que a obtenção de dados sobre a utilização de derivativos diretamente do balanço anual das empresas impõe uma possível limitação ao estudo. Existe a possibilidade de que algumas empresas usuárias de derivativos não venham a declarar a utilização destes em suas notas explicativas. Dessa maneira, a variável construída poderia medir a qualidade do disclosure da firma e não somente a política financeira da firma. Portanto, surveys realizadas diretamente com as empresas podem obter dados mais precisos sobre as práticas desenvolvidos pelos gestores das firmas.

\section{REFERÊNCIAS}

ALLAYANNIS, G; LEL, U; MILLER, D. Corporate governance and the hedging premium around the world. Working paper, Darden Business School, Virginia, USA, 2007. Disponível em http://papers.ssrn.com/sol3/papers cfm?abstract_id=460987. Acesso em 07.07.2008.

ALLAYANNIS, G; WESTON, J. The use of foreign derivatives and firm market value. The Review of Financial Studies, v. 14, n. 1, p. 243-276, 2001

BERGER, P; OFEK, E. Diversification's effect on firm value. Journal of Financial Economics, v. 37, n. 1, p. 39-65, 1995.

BODNAR, G; TANG, C; WEINTROP, E. J. Both sides of corporate diversification: the value impact of geographical and industrial diversification. Working paper, Wharton Business School, Pennsylvania, USA 1999. Disponivel em http://papers.ssrn.com/sol3/papers.cfm?abstract_ id=217869. Acesso em 07.07.2008.

CARTER, D; ROGERS, D; SIMKINS, B. Does hedging affect firm value? Evidence from the US airline industry. Financial Management, v. 35, n 1, p. 53-86, 2006.

CHUNG, K; PRUITT, S. A simple approximation of Tobin's Q. Financial Management, v. 23, n. 3, p. 70-74, 1994.

CVM - COMISSÃO DE VALORES MOBILIÁRIOS. Instrução n. 235 , 1995

DAN, C; GU, H; XU, K. The impact of hedging on stock return and firm value: new evidence from Canadian oil and gas companies. Working paper, Dalhousie University, Halifax, Canada, 2005. Disponível em http://economics.dal.ca/RePEc/dal/wparch/hedging.pdf. Acesso em 07.07.2008.

DEMARZO, P; DUFFIE, D. Corporate incentives for hedging and hedge accounting. The Review of Financial Studies, v. 8, n. 3, p. 743-771, 1995.

FAMÁ, R; BARROS, L. Q de Tobin e seu uso em finanças: aspectos metodológicos e conceituais. Caderno de Pesquisas em Administração, v. 7, n 4, p. $27-43,2000$ 


\section{JOSÉ LUIZ ROSSI JÚNIOR}

FROOT, K; SCHRFSTEIN, D; STEIN, J. Risk management: coordinating corporate investment and financing policies. The Journal of Finance, v. 48, n. 5 , p. $1629-1658,1993$

HAGELIN, N. Hedging foreign exchange exposure: risk reduction from transaction and translation hedging. Journal of International Financial Management and Accounting, v. 15, n. 1, p. 1-20, 2004.

HAGELIN, N; HOLMEN, M, KNOPF, J; PRAMBORG, B. Managerial stock option and the hedging premium. Working paper, Stockholm University, Stockholm, Sweden, 2004. Disponível em http://papers.ssrn.com/sol3/ papers.cfm?abstract_id=585641. Acesso em 07.07.2008.

HAGELIN, N. Why firms hedge with currency derivatives: an examination of transaction and translation exposure. Applied Financial Economics, v. 13, n. 1, p. 55-69, 2001.

JENSEN, M. Agency costs of free cash flow, corporate finance and takeovers. American Economic Review, v. 76, n. 2, p. 323-329, 1986.

JIN, Y; JORION, P. Firm value and hedging: evidence from U.S. oil and gas producers. The Journal of Finance, v. 61, n. 2, p. 893-919, 2004.

JUDGE, A. Why do firms hedge? A review of the evidence. Working paper, Middlesex University, London, England, 2003. Disponível em http://papers.ssrn.com/sol3/papers.cfm?abstract_id=899632. Acesso em 07.07.2008.

LANG, L; STULZ, R. Tobin's Q, corporate diversification and firm performance. Journal of Political Economy, v. 102, n. 6, p. 1248-1280, 2004.

LOOKMAN, A. Does hedging increase firm value? evidence from oil and gas producing firms. Working paper, Tepper School of Business, Carnegie Mellon University, Pittsburgh, Pennsylvania, USA, 2004. Disponível em http://www.fdic.gov/bank/analytical/CFR/2004/sept/CFRCP_2004-09_ Lookman.pdf. Acesso em 07.07.2008.

MODIGLIANI, F; MILLER, M. The cost of capital, corporation finance and the theory of investment. American Economic Review, v. 48, n. 3, p. 261-297, 1958.
MORCK, Y; YEUNG, B. Why investors value multinacionality. Journal of Business, v. 64, n. 2, p. 165-187, 1991.

PELTZMAN, S. The gains and losses from industrial concentration. Journal of Law and Economics, v. 20, n. 2, p. 229-263, 1977.

PRAMBORG, B. Derivatives hedging, geographical diversification, and firm market value. Journal of Multinational Financial Management, v. 14, n. 2 , p. 117-133, 2004.

ROSSI, J. The use of currency derivatives by Brazilian companies: an empirical investigation. Revista Brasileira de Finanças, v. 5, n. 2, p. 205-232, 2007.

SAITO, R; SCHIOZER, R. Uso de derivativos em empresas não-financeiras listadas em bolsa no Brasil. RAUSP - Revista de Administração, v. 42, n. 1, p. 97-107, 2007.

SAITO, R; SCHIOZER, R. Why do Latin American firms manage currency risks? Emerging Markets Finance and Trade (no prelo), 2008.

SCHNEIDER, M; TORNELL, A. Balance-sheet effects, bailout guarantees and financial crises. Review of Economic Studies, v. 71, n. 3, p. 883-913, 2004 .

SHIN, H; STULZ, R. Firm value, risk and growth opportunities. Working paper, National Bureau of Economic Research (NBER), Cambridge Massachusets, USA, 2000. Disponivel em http://papers.ssrn.com/sol3/ papers.cfm?abstract_id=236869. Acesso em 07.07.2008.

SMITH, C; STULZ, R. The determinants of firms hedging policies. Journal of Financial and Qualitative Analysis, v. 20, n. 4, p. 391-405, 1985.

STULZ, R. Optimal hedging policies. Journal of Financial and Quantitative Analysis, v. 19, n. 2, p. 127-140, 1984. 